Wright State University

CORE Scholar

Physics Faculty Publications

Physics

$1-1-2001$

\title{
Evolution of Deep Centers in GaN Grown by Hydride Vapor Phase Epitaxy
}

Z-Q. Fang

David C. Look

Wright State University - Main Campus, david.look@wright.edu

J. Jasinski

M. Benamara

Z. Liliental-Weber

See next page for additional authors

Follow this and additional works at: https://corescholar.libraries.wright.edu/physics

Part of the Physics Commons

\section{Repository Citation}

Fang, Z., Look, D. C., Jasinski, J., Benamara, M., Liliental-Weber, Z., \& Molnar, R. J. (2001). Evolution of Deep Centers in GaN Grown by Hydride Vapor Phase Epitaxy. Applied Physics Letters, 78 (3), 332-334. https://corescholar.libraries.wright.edu/physics/69

This Article is brought to you for free and open access by the Physics at CORE Scholar. It has been accepted for inclusion in Physics Faculty Publications by an authorized administrator of CORE Scholar. For more information, please contact library-corescholar@wright.edu. 
Authors

Z-Q. Fang, David C. Look, J. Jasinski, M. Benamara, Z. Liliental-Weber, and Richard J. Molnar

This article is available at CORE Scholar: https://corescholar.libraries.wright.edu/physics/69 


\title{
Evolution of deep centers in GaN grown by hydride vapor phase epitaxy
}

\author{
Z.-Q. Fang ${ }^{\text {a) }}$ and D. C. Look ${ }^{\text {a) }}$ \\ Semiconductor Research Center, Wright State University, Dayton, Ohio 45435 \\ J. Jasinski, M. Benamara, and Z. Liliental-Weber \\ Lawrence Berkeley National Laboratory, Berkeley, California 94720 \\ R. J. Molnar \\ Lincoln Laboratory, Massachusetts Institute of Technology, Lexington, Massachusetts 02173
}

(Received 9 October 2000; accepted for publication 15 November 2000)

\begin{abstract}
Deep centers and dislocation densities in undoped $n \mathrm{GaN}$, grown by hydride vapor phase epitaxy (HVPE), were characterized as a function of the layer thickness by deep level transient spectroscopy and transmission electron microscopy, respectively. As the layer thickness decreases, the variety and concentration of deep centers increase, in conjunction with the increase of dislocation density. Based on comparison with electron-irradiation induced centers, some dominant centers in HVPE GaN are identified as possible point defects. () 2001 American Institute of Physics.
\end{abstract}

[DOI: $10.1063 / 1.1338970]$

Hydride vapor phase epitaxy (HVPE) is a promising technique for growing thick GaN layers to be used as substrates for the subsequent growth of device structures. The material quality of HVPE GaN has been found to improve greatly with thickness, mainly because of the presence of a highly defected layer at the GaN sapphire interface. ${ }^{1-4}$ In an earlier study, ${ }^{3}$ deep centers in a 13 - $\mu$ m-thick GaN film grown by HVPE on GaCl-pretreated sapphire were characterized by deep level transient spectroscopy (DLTS). It was found that both the species and the concentrations of the detected deep centers were nearly constant as the film was thinned by mechanical polishing from the original thickness to a thickness of $\sim 1.2 \mu \mathrm{m}$. Recently, we have conducted a comprehensive study of impurities and defects in undoped $n$-GaN grown by HVPE. The material quality was characterized by many techniques, including electrical, optical, chemical, and structural methods. The nominal thickness of the layers varied from 1 to $68 \mu \mathrm{m}$, depending on growth time. Five samples, with layer thicknesses ranging from 5 to $68 \mu \mathrm{m}$, were chosen for DLTS characterization. Two samples, with nominal thicknesses of $5 \mu \mathrm{m}$ and $68 \mu \mathrm{m}$, were selected for transmission electron microscopy (TEM) characterization. In this letter, we present the evolution of deep centers (both in species and concentrations) as layer thickness is reduced. The possible identities of the dominant centers will be discussed based on a comparison with electronirradiation (EI) induced centers, and the correlation of DLTS centers with the threading dislocation density measured by TEM.

The GaN layers used in this study were grown on $\mathrm{ZnO}$ pretreated sapphire in a chloride-transport HVPE vertical reactor. Details of the GaN growth and the sapphire pretreatment techniques are described elsewhere. ${ }^{4}$ Scanning electron microscopy was used to measure the layer thicknesses, which usually varied somewhat within a wafer. For capacitance-voltage $(C-V)$ and DLTS studies, five samples

${ }^{a)}$ Also at: Material and Manufacturing Directorate, Air Force Research Laboratory, Wright-Patterson Air Force Base, Ohio 45433. with nominal thicknesses of $5,11,15,39$, and $68 \mu \mathrm{m}$ were used. Schottky barrier diodes (SBDs), with planar structures on the top surface, were fabricated by using electron-beam and thermal evaporations and lithographic processing. In the planar structure, small Ni/Au Schottky contacts with diameters of $250 \mu \mathrm{m}$ were surrounded by large-area $\mathrm{Ti} / \mathrm{Al} / \mathrm{Ti} / \mathrm{Au}$ ohmic contacts. A Bio-Rad DL4600 system with a 100-mV test signal at $1 \mathrm{MHz}$ was used to take $C-V$ and DLTS data. To determine the activation energy $E_{T}$ of the deep centers, the DLTS spectra were taken at different rate windows, from 0.8 to $200 \mathrm{~s}^{-1}$, and were analyzed by the standard Arrhenius technique. For TEM studies, two samples with nominal thicknesses of $5 \mu \mathrm{m}$ and $68 \mu \mathrm{m}$ were selected, and cross sectional specimens were prepared. In order to obtain electron transparent areas from all parts of the $68 \mu \mathrm{m}$ layer, the sample was ion milled down successively in several steps.

Carrier concentrations in the top regions of the five samples, determined by $C-V$ measurements, were found to be in the $10^{17} \mathrm{~cm}^{-3}$ range; these results are similar to those found by Hall effect measurements, corrected for the degenerate interface layer. ${ }^{2}$ Without this correction, the "apparent" (average) Hall carrier concentration for the $5 \mu \mathrm{m}$ sample was quite high, about $1.1 \times 10^{18} \mathrm{~cm}^{-3}$. As the sample thickness decreased from 68 to $5 \mu \mathrm{m}$, the apparent (average) mobility dropped from 740 to $190 \mathrm{~cm}^{2} / \mathrm{V}$ s, which are similar numbers to those reported in Ref. 3. For the three thickest samples $(68-13 \mu \mathrm{m})$, the apparent carrier concentrations were found to increase from $1.3 \times 10^{17}$ to $2.6 \times 10^{17} \mathrm{~cm}^{-3}$. Typical current-voltage $(I-V)$ characteristics, measured at $300 \mathrm{~K}$ for those three samples, are shown in Fig. 1. It can be seen that the reverse leakage currents, which show typical electric-field enhanced soft-breakdown characteristics (believed to be related to carrier tunneling or hopping through defect states associated with threading dislocations), are significantly reduced by almost three orders of magnitude due to the increase of layer thickness. Forward $I-V$ characteristics, described by an ideality factor $n$, are also affected; i.e., the thicker the layer, the closer the $n$ value to unity. These results imply that dislocation densities in the top regions of 


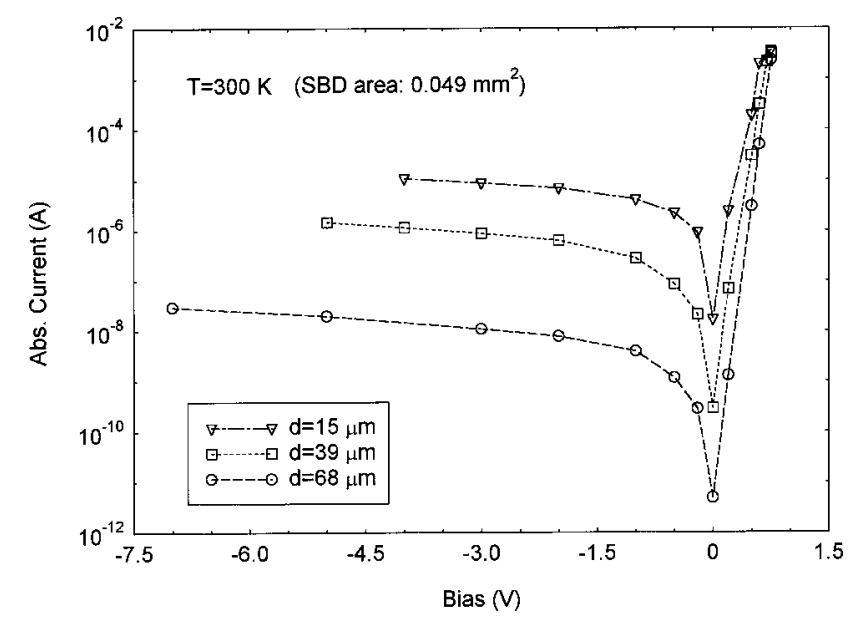

FIG. 1. Typical $I-V$ characteristics of SBDs on HVPE-GaN with different thicknesses.

the samples are reduced with increasing thickness, which is verified in the TEM images presented as follows. Typical DLTS spectra for all five samples are presented in Fig. 2. Note that the spectra in Fig. 2 have different base lines, separated by $0.5 \times 10^{14} \mathrm{~cm}^{-3}$. From Fig. 2, we see that: (i) for the two thickest samples (see curves a and b), the dominant centers are $A_{x}\left(E_{T} \sim 0.72 \mathrm{eV}\right), A\left(E_{T}=0.67 \mathrm{eV}\right)$, and $B\left(E_{T}=0.61 \mathrm{eV}\right)$, with concentrations in the $10^{13}-10^{14} \mathrm{~cm}^{-3}$ range, (ii) for the $15-\mu \mathrm{m}$ sample (see curve c), a center with $E_{T}=0.20 \mathrm{eV}$ (labeled as $D$ ) appears at low temperatures, (iii) for the $11-\mu \mathrm{m}$ sample (see curve d), in addition to a center with $E_{T}=0.17 \mathrm{eV}$ (also labeled as $D$ ) at low temperatures, the center $A_{1}\left(E_{T}=0.89 \mathrm{eV}\right)$, with a higher concentration in the $10^{14}-10^{15} \mathrm{~cm}^{-3}$ range, arises, and (iv) for the 5 - $\mu \mathrm{m}$ sample (see curve e), $B$ becomes a prominent center and $A_{1}$ drops significantly, as compared to its value in the 11- $\mu \mathrm{m}$ sample, and the other observed centers are $A, C$ $\left(E_{T}=0.41 \mathrm{eV}\right)$, and $D\left(E_{T}=0.23 \mathrm{eV}\right)$. Thus, we can state that as the HVPE-GaN samples become thinner, both the species and concentrations of the deep centers increase. Interestingly, most of deep centers found in HVPE GaN have been also observed by us in $n \mathrm{GaN}$ grown by other techniques, such as metalorganic chemical vapor deposition (MOCVD) and reactive molecular beam epitaxy (RMBE).

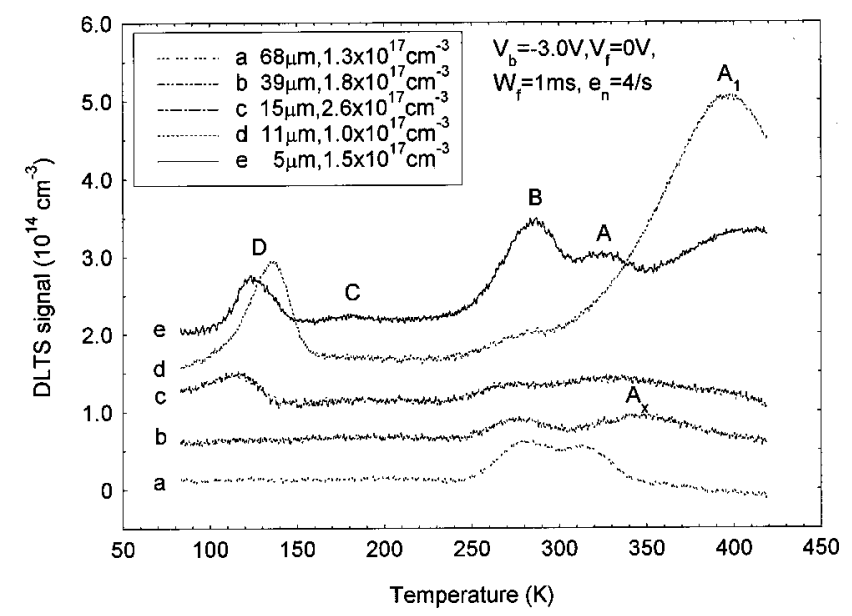

FIG. 2. Typical DLTS spectra for HVPE-GaN samples with different thicknesses. The carrier concentration of each sample is shown in the legend.
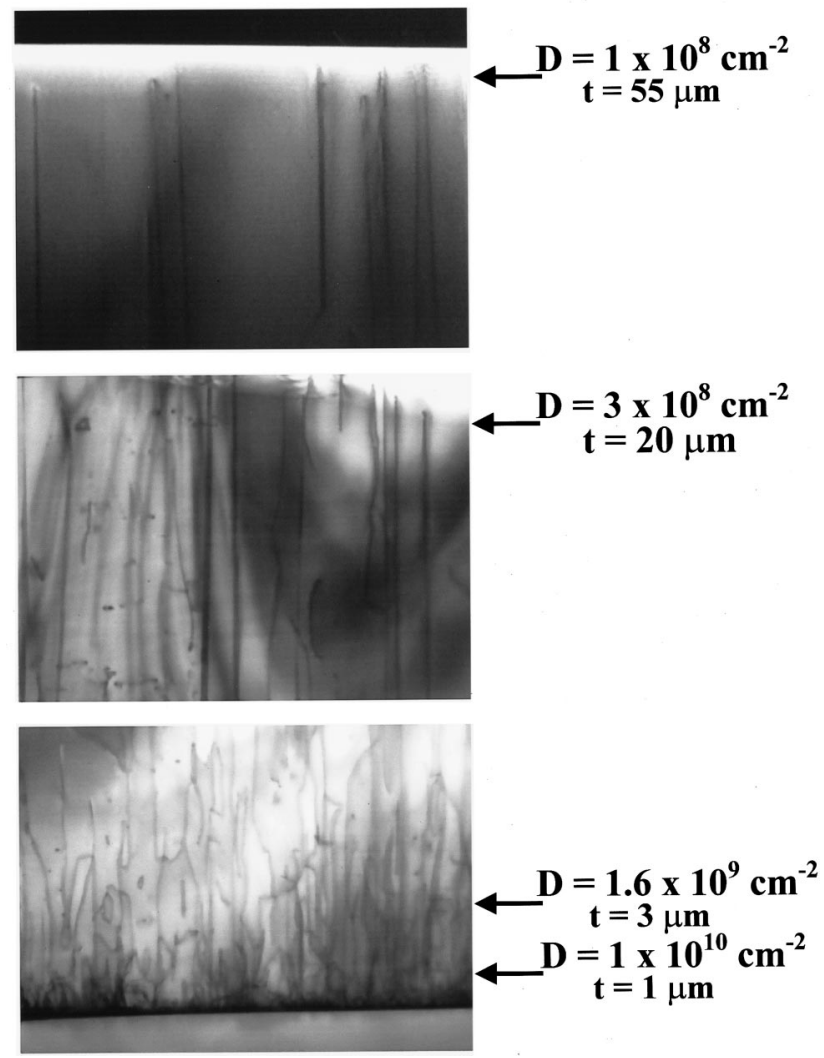

FIG. 3. Cross sectional TEM images of a thick HVPE-GaN sample: (a) in the top region, (b) in the middle region, and (c) in the region close to $\mathrm{GaN}$ sapphire interface.

Depending on the material quality (like the layer thickness, electron mobility, and dislocation density), the concentrations of these deep centers can be as low as $10^{13}-10^{14} \mathrm{~cm}^{-3}$ for a 4.5- $\mu \mathrm{m}$-thick MOCVD GaN, with an electron mobility of $765 \mathrm{~cm}^{2} / \mathrm{V} \mathrm{s}$ and an estimated dislocation density of low$10^{8} \mathrm{~cm}^{-2}$, and as high as $10^{15}-10^{16} \mathrm{~cm}^{-3}$ for $0.5-\mu \mathrm{m}-$ thick RMBE-GaN layers, with electron mobilties below 250 $\mathrm{cm}^{2} / \mathrm{V} \mathrm{s}$ and dislocation densities in the $10^{9}-10^{10} \mathrm{~cm}^{-2}$ range. 5

Cross sectional TEM images, corresponding to three different regions of the nominally $68 \mu \mathrm{m}$ thick sample (the real thickness, $t$, of the TEM sample is $55 \mu \mathrm{m}$ ) are shown in Fig. 3. As indicated in Fig. 3, the dislocation densities clearly increase from $1 \times 10^{8}$ in the top region (at $t=55 \mu \mathrm{m}$ ), up to $3 \times 10^{8} \mathrm{~cm}^{-2}$ in the middle region (at $t=20 \mu \mathrm{m}$ ), then up to $1.6 \times 10^{9}$ and $1 \times 10^{10} \mathrm{~cm}^{-2}$ in the region close to the interface (at $t=3 \mu \mathrm{m}$ and $1 \mu \mathrm{m}$, respectively). From a cross sectional TEM image for the nominally $5 \mu \mathrm{m}$ thick sample (not shown here), the dislocation densities at $t=4.5 \mu \mathrm{m}, 3$ $\mu \mathrm{m}$, and $1 \mu \mathrm{m}$, are $9 \times 10^{8} \mathrm{~cm}^{-2}, 1.7 \times 10^{9} \mathrm{~cm}^{-2}$, and 4 $\times 10^{9} \mathrm{~cm}^{-2}$, respectively. The fact that the results obtained on the $5 \mu \mathrm{m}$ thick sample are very similar to those obtained in the interface region of the $55 \mu \mathrm{m}$ thick sample implies a fairly good reproducibility of HVPE growth. Therefore, the dislocation densities in the top regions of all five samples can be considered to be roughly the same as those measured at corresponding thicknesses in the thickest sample. By comparing these three experimental results (i.e., the increase of the reverse leakage current of the SBDs, the evolution of the deep centers, and the increase of dislocation density, with decreasing thickness), it appears that the formation of deep 
centers in HVPE-GaN layers is closely associated with the presence of threading dislocations.

Experimentally, threading dislocations in GaN are electrically active, providing defect states and acting as traps and nonradiative recombination centers, which have been demonstrated by studies of scanning capacitance microscopy ${ }^{6}$ and plan-view TEM along with cathodoluminescence imaging. ${ }^{7}$ Recently, a theory of charged-dislocation line scattering was developed within the framework of the Boltzmann transport equation. ${ }^{8} \mathrm{~A}$ fit of the theory to temperaturedependent Hall effect data in $\mathrm{GaN}$ gave dislocation densities in excellent agreement with those measured by TEM. Theoretically, threading dislocations in $\mathrm{GaN}$ have been predicted to have $V_{\mathrm{Ga}}$ or $V_{\mathrm{N}}$ defects in their core structures, depending on doping (or type) and growth stoichiometry; i.e., formation of the $V_{\mathrm{Ga}}$ structure is favored under N-rich conditions and is most stable in $n$-type material, whereas formation of the $V_{\mathrm{N}}$ structure is favored under Ga-rich conditions and is most stable in $p$-type material. ${ }^{9}$ Because of the uncertainty in the formation energy calculations, a mixture of core structures is also possible. Thus, edge dislocations are predicted to behave as electron traps in $n$-type GaN and may act as hole traps in $p$-type $\mathrm{GaN}$, depending on growth conditions. To discuss the possible point defect natures of the main centers found in $n \mathrm{GaN}$, we emphasize two important experimental facts: (i) high concentrations of deep centers in $n \mathrm{GaN}$ are closely associated with high dislocation densities, no matter what growth technique is used, and (ii) there exists an anticorrelation relationship between centers $A_{1}$ and $B$ for the two thinnest samples (see curves $d$ and e in Fig. 1). The anticorrelation relationship was also observed in other $n$-GaN materials (e.g., for thin MOCVD GaN, see Fig. 4 in an earlier study, ${ }^{10}$ and for thin RMBE GaN, see Figs. 3 and 4 in Ref. 5), which means that a strong increase in $\operatorname{trap} B$ is usually accompanied by a significant reduction of trap $A_{1}$. The center $B$ (also named $E 2$ in the literature) has been extensively studied. Earlier studies suggested that the center could be due to chemical impurities, like C (Ref. 11) or $\mathrm{Mg}$ (Ref. 12). In a later investigation, the photoionization of $E 2$ in $n \mathrm{GaN}$ was characterized by using capacitance transient spectroscopy, yielding an optical activation energy of $E^{o}$ $=0.85 \mathrm{eV}$ at $90 \mathrm{~K}$ and resulting in a Franck-Condon shift of $0.3 \mathrm{eV}$, indicating a possible defect nature. ${ }^{13}$ A recent study showed that E2 could be effectively suppressed by isoelectronic In doping and it was suspected of being $\mathrm{N}_{\mathrm{Ga}}$ defect. ${ }^{14}$ To understand the nature of $A_{1}$, we need to recall the EI induced centers in $n$ GaN. In a DLTS study of MOCVD$\mathrm{GaN}$ after 1-MeV electron irradiation, we found two EI induced centers: trap $E$ (at $\sim 120 \mathrm{~K}$ ), which consisted of two components, with each having a thermal activation energy of $0.06 \mathrm{eV}$; and trap $A_{2}$ (at $\sim 420 \mathrm{~K}$ ), with $E_{T}=0.85 \mathrm{eV}$. There is good evidence that $E$ is related to the nitrogen vacancy $\left(V_{\mathrm{N}}\right)$, and because $A_{2}$ shows a production rate close to that of $E$, it is possible that $A_{2}$ might be a $N_{\text {I }}$ related defect, created by the reaction $N_{\mathrm{N}} \rightarrow V_{\mathrm{N}}+N_{\mathrm{I}} .{ }^{5}$ In the study of EI, we also found that some pre-existing centers in MOCVD-GaN, including $B$, are not affected by $1-\mathrm{MeV}$ EI at all, thus ruling out the possibility of $B$ being related to a $V_{\mathrm{N}}$ defect. Since center $A_{1}$ is very similar to the EI induced center $A_{2}$ and since $B$ shows an anticorrelation with $A_{1}$, we tentatively assign $A_{1}$ to a $N_{\mathrm{I}}$ related defect and $B$ to $\mathrm{N}_{\mathrm{Ga}} \cdot \mathrm{N}_{\mathrm{Ga}}$ can be easily formed by the reaction $V_{\mathrm{Ga}}+N_{\mathrm{I}} \rightarrow N_{\mathrm{Ga}}$. According to the theoretical prediction mentioned above, $V_{\mathrm{Ga}}$ should be available in $n \mathrm{GaN}$ with a high dislocation density. Indeed, the presence of $V_{\mathrm{Ga}}$ in undoped MOCVD-GaN has been verified by positron annihilation spectroscopy. ${ }^{15}$ The center $D$, with $E_{T}=0.17-0.23 \mathrm{eV}$, also shows a correlation with the thickness reduction or the dislocation increase, which means that $D$, as an electron trap, could possibly be a defect complex involving $V_{\mathrm{Ga}}$ (such as $V_{\mathrm{N}}-V_{\mathrm{Ga}}$ ).

In summary, HVPE-grown $n$-GaN layers with different thicknesses have been characterized by DLTS and TEM. As the layer thickness decreases, an increase of deep centers, both in species and concentrations, was clearly observed, which is believed to be closely associated to the significant increase of threading dislocations in the regions near the $\mathrm{GaN} / \mathrm{sapphire}$ interface. Based on a comparison with EI induced centers and an observation of anticorrelation, $A_{1}$ is tentatively assigned to $N_{\mathrm{I}}$, and $B$ to $N_{\mathrm{Ga}}$.

Two of the authors (Z.-Q.F. and D.C.L.) were supported under U.S. Air Force Contract No. F33615-95-C-1619, including partial support from the Air Force Office of Scientific Research, and U.S. Navy Contract N0001499-1-1067. The authors would like to thank $\mathrm{C}$. Lu for fabricating the SBDs and T. Cooper for Hall-effect measurements. TEM group (J.J., M.B., and Z.L.-W.) was supported by the Air Force Office of Scientific Research, through the U.S. Department of Energy under Order No. AFOSR-ISSA-00-0011. They also want to thank NCEM in Berkeley for use of the TEM facility and W. Swider for excellent sample preparation. Another author (R.J.M.) was supported by the Office of Naval Research under Air Force Contract No. F19628-00-C0002. Opinions, interpretations, and conclusions are those of the authors and not necessarily endorsed by the U.S. Air Force.

${ }^{1}$ W. Götz, J. Walker, L. T. Romano, N. M. Johnson, and R. J. Molnar, Mater. Res. Soc. Symp. Proc. 449, 525 (1997).

${ }^{2}$ D. C. Look and R. J. Molnar, Appl. Phys. Lett. 70, 3377 (1997).

${ }^{3}$ W. Götz, L. T. Romano, J. Walker, N. M. Johnson, and R. J. Molnar, Appl. Phys. Lett. 72, 1214 (1998).

${ }^{4}$ R. J. Molnar, W. Götz, L. T. Romano, and N. M. Johnson, J. Cryst. Growth 178, 147 (1997).

${ }^{5}$ Z.-Q. Fang, L. Polenta, J. W. Hemsky, and D. C. Look, Proceedings of the 11th Conference on Semiconducting and Insulating Materials (SIMC-XI) (Canberra, Australia, 2000) (to be published).

${ }^{6}$ P. J. Hansen, Y. E. Strausser, A. N. Erickson, E. J. Tarsa, P. Kozodoy, E. G. Brazel, J. P. Ibbetson, U. Mishra, V. Narayanamurti, S. P. DenBaars, and J. S. Speck, Appl. Phys. Lett. 72, 2247 (1998).

${ }^{7}$ T. Sugahara, H. Sato, M. Hao, Y. Naoi, S. Kurai, S. Tottori, K. Yamashita, K. Nishino, L. T. Romano, and S. Sakai, Jpn. J. Appl. Phys., Part 2 37, L398 (1998).

${ }^{8}$ D. C. Look and J. R. Sizelove, Phys. Rev. Lett. 82, 1237 (1999).

${ }^{9}$ A. F. Wright and U. Grossner, Appl. Phys. Lett. 73, 2751 (1998).

${ }^{10}$ W. Götz, N. M. Johnson, D. P. Bour, C. Chen, H. Liu, C. Kuo, and W. Imler, Mater. Res. Soc. Symp. Proc. 395, 443 (1996).

${ }^{11}$ W. I. Lee, T. C. Huang, J. D. Guo, and M. S. Feng, Appl. Phys. Lett. 67, 1721 (1995).

${ }^{12}$ P. Hacke, H. Nakayama, T. Detchprohm, K. Hiramatsu, and N. Sawaki, Appl. Phys. Lett. 68, 1362 (1996).

${ }^{13}$ P. Hacke, P. Ramvall, S. Tanaka, Y. Aoyagi, A. Kuramata, K. Horino, and H. Munekata, Appl. Phys. Lett. 74, 543 (1999).

${ }^{14}$ H. M. Chung, W. C. Chuang, Y. C. Pan, C. C. Tsai, M. C. Lee, W. H. Chen, W. K. Chen, C. I. Chiang, C. H. Lin, and H. Chang, Appl. Phys. Lett. 76, 897 (2000).

${ }^{15}$ K. Saarinen, P. Seppälä, J. Oila, P. Hautojärvi, C. Corbel, O. Briot, and R. L. Aulombard, Appl. Phys. Lett. 73, 3253 (1998). 